\title{
Fast Transmission Electron Microscope (TEM) Technique for Observing Isolated Mitochondria of Soybean (Glycine max (L.) Merr.) in about Six Hours
}

Hugolino Cardenas Colmenares*

Faculty of Agriculture, Plant Physiology, Botany Department, Maracay, Aragua, Venezuela

\begin{abstract}
In his PhD thesis presented different studies designed to define methods for the study of the basic, intracellular mode of action of herbicides at very low doses, and to test these on two commercial herbicides simazine and bentazone, in soybean cell suspensions, consisting primarily of single cells with a few clumps.

To determine the progressive herbicidal damage of fine structure as dose increased a fast technique for TEM observations was developed. The technique is based on procedures already proved for human leukocytes and in animal tissue. This technique, presented here in detail, allowed to treat the single cells with the herbicides mentioned above for 40 minutes, fix, dehydrate, embed, and get the blocks ready for sectioning in about six hours. The same fast technique also allowed to observe the integrity of isolated soybean mitochondria previous to the citochrome $c$ oxidase studies

The great similarity existing among plant, human and animal mitochondria has being observed long time ago. It seems reasonable to think that the fast technique, mentioned above, to observe the soybean mitochondria, could be useful, once adapted, to study human and animal mitochondria, due to the great similarity among the mentioned organelles.
\end{abstract}

Keywords: Herbicides; Fast Transmission Electron Microscope (TEM); Human and animal mitochondria

\section{Introduction}

The present article is based on the thesis: Some effects of low doses of simazine and bentazone on fine structure and metabolism of soybean cells [1-3]. The great similarity existing among plant, human and animal mitochondria has being observed long time ago [4]

The modern medicine studies the dysfunction of human mitochondria in connection to several diseases. For instance, Rugarli and Langer [5] wrote: "Mitochondrial integrity and functionality is monitored via multiple levels of cellular and organellar quality control that critically depend on mitochondrial proteases. Defects in these surveillance mechanisms cause neuronal loss in a number of prevalent neurodegenerative diseases."

It seems reasonable to think that the fast technique for TEM developed by Cardenas [1] for his thesis, and presented here, could be useful, once adapted, in studies on human and animal mitochondria due to the great similarity among the mentioned organelles. The technique allowed to process, in about six hours, the pellets of both soybean isolated mitochondria and isolated cells, for their observation with the TEM.

\section{Materials and Methods}

\section{Chemicals}

Both organic and inorganic chemicals were analytical reagent grade and glass distilled water was used throughout. Soybean seeds cultivar Fiskerby $\mathrm{V}$ were used in the present studies.

\section{Experiments defining essential techniques}

Seed sterilization:

A) Ethanol followed by a commercial formulation of sodium hypochlorite (BDH): All operations were carried out in a sterile airflow cabinet. After the dry seeds had been shaked for two minutes in a conical flask with $70 \%$ ethanol, the alcohol was drained off and the seeds immersed in the hypochlorite solution, diluted to give 1.0 to $1.4 \%$ $(\mathrm{w} / \mathrm{v})$, for 15 minutes with gentle shaking. The seeds were then rinsed four times in sterile distilled water. Sterilized seeds were placed on sterile filter paper in petri dishes or on a ball of brown or white cotton in sterile test tubes adding adequate amounts of sterile distilled water for seed germination, a procedure similar to that described by Gambor [6]. Test tubes were sealed with sterile $7 \times 7 \mathrm{~cm}$ squares of polypropylene sheet and a rubber band, and placed in the dark at $27.5^{\circ} \mathrm{C}$.

B) Mercuric chloride: An aqueous $0.1 \%$ solution $[7,8]$ sufficient to cover the seeds was added to the conical flask. After a manual shaking for 5 minutes, the mercuric solution was drained and the seeds gently shaken with 3 or more changes of sterile distilled water for 1 minute each. Two sterile seeds were placed in each sterile test tube containing about $5 \mathrm{ml}$ of water on a white cotton ball and allowed to germinate in the dark at $27.5^{\circ} \mathrm{C}$ in an incubator.

\section{Callus initiation}

Cotyledons were aseptically excised from 8 to 11 days old soybean seedlings and placed on a sterile polypropylene sheet over a piece of square paper on a tile of the type used for dissections. Each

*Corresponding author: Hugolino Cardenas Colmenares, Professor, Faculty of Agriculture, Plant Physiology, Botany Department, Maracay Aragua, Venezuela E-mail: hugolinoc6@gmail.com

Received March 26, 2013; Accepted June 26, 2013; Published June 28, 2013

Citation: Colmenares HC (2013) Fast Transmission Electron Microscope (TEM) Technique for Observing Isolated Mitochondria of Soybean (Glycine max (L.) Merr.) in about Six Hours. Adv Pharmacoepidem Drug Safety 2: 136. doi:10.4172/21671052.1000136

Copyright: (c) 2013 Colmenares HC. This is an open-access article distributed under the terms of the Creative Commons Attribution License, which permits unrestricted use, distribution, and reproduction in any medium, provided the original author and source are credited. 
cotyledon was transversely cut into six pieces which were transferred individually to test tubes having $10 \mathrm{ml}$ of 1 -B5 medium containing 1 $\mathrm{mg} / \mathrm{l}$ of 2,4-dichlorofenoxiacetic acid (2,4-D), but no kinetin, both in continuous light or dark at $23^{\circ} \mathrm{C}$.

As a routine practice, after several experiments, on the effect of the cotyledonary epidermis on callus growth, both surfaces of the cotyledons were scraped before sectioning.

Murashige and Skoog's medium with $0.5 \mathrm{mg} / \mathrm{l} 2,4-\mathrm{D}$ and $0.1 \mathrm{mg} / \mathrm{l}$ of kinetin [9] was used instead of 1-B5 in further callus initiation in the light at $23^{\circ} \mathrm{C}$. Subcultures were made every 14 days.

\section{Determination of the integrity of isolated mitochondria}

The procedures described by Axelrod [10] for extraction of mitochondria were tried in combination with the fast technique for fixing and embedding for electron microscopy. According to Bonner (1973) $1 \mathrm{~g}$ of callus was homogenized in $10 \mathrm{ml}$ of grinding medium $(0.3$ M mannitol; $1.0 \mathrm{M}$ EDTA; 0.1\% BSA; 0.05\% cysteine; $\mathrm{pH} 7.2$ ) and the homogenate centrifugated at $1000 \times \mathrm{g}$ for 15 minutes; the supernatant was centrifugated at $1000 \times \mathrm{g}$ for 20 minutes; the pellet resuspended in washing medium (0.3 M mannitol; $1.0 \mathrm{mM}$ EDTA; 0.1\% BSA; $\mathrm{pH}$ 7.2 ) and centrifuged at $250 \times \mathrm{g}$ for 10 minutes; the supernatant was centrifuged at $6000 \mathrm{~g}$ x 15 minutes and the pellet processed for electron microscopy.

According to Axelrod [10] the extracting medium consisted of $0.4 \mathrm{M}$ sucrose, $0.01 \mathrm{M}$ P04 buffer $\mathrm{pH} 7.1$ in $0.4 \mathrm{M}$ sucrose. Initial centrifugation was $500 \times \mathrm{g}$ for 5 minutes; the pellet resuspended in sucrose buffer and centrifuged at $1000 \mathrm{~g} \times 15$ minutes and the mitochondrial pellet processed for electron microscopy.

\section{Electron microscopy}

The fast method described here allowed treatment with herbicides, fixation, dehydration, embedding and polymerization of the block of isolated mitochondria as well as cell suspensions to be completed in about six hours. The materials were essentially the same as those used in the conventional technique for the preparation of plant material for TEM studies. The fast technique is a combination of methods which were shown to be satisfactory by several authors $[2,3,11,12]$. In the following description of the overall procedure details of the preparation of materials used are explained first, and then in Table 1 the preparations of solutions, amounts, time of treatments and references for each one of the steps of the TEM preparation are shown.

\section{Preparation of materials:}

a) Sodium cacodylate buffer: The $0.1 \mathrm{M}$ buffer was prepared by dissolving $4.28 \mathrm{~g}$ of sodium cacodylate in $200 \mathrm{ml}$ of glass distilled water adjusting the $\mathrm{pH}$ to 7.4 [12].

b) Osmium tetroxide $2 \%$ solution: A $0.2 \mathrm{~g}$ of $\mathrm{Os}_{4}$ ampoule was immersed in water until the label was completely separated and the sticker removed. The ampoule being handled with a pair of forceps to avoid organic deposits on the glass was then placed inside an amber glass bottle containing $10 \mathrm{ml}$ of sodium cacodylate buffer and then crushed with a glass rod leaving the remains of the ampoule inside. The operation was performed in a fume cupboard and the bottle was closed with an amber glass stopper.

c) Glutaraldehyde $2.5 \%$ solution: The available glutaraldhyde was $24.6 \%$ in strength and this concentration was taken as $25 \%$. One $\mathrm{ml}$ of glutaraldehyde was poured into a test tube containing $9 \mathrm{ml}$ of the

\begin{tabular}{|c|c|c|c|c|}
\hline & Fixation & Washing & Uranyl Acetate & Dehydration 1 \\
\hline Prepare & $\begin{array}{l}2.5 \% \text { glutaralde- } \\
\text { hyde \& } 2 \% \mathrm{OsO}_{4} \\
\text { in } 0.1 \mathrm{M} \\
\text { cacodylate buffer, } \\
\mathrm{pH} 7.4\end{array}$ & $\begin{array}{l}\text { Glass } \\
\text { Distilled } \mathrm{H}_{2} \mathrm{O}\end{array}$ & $2 \%$ in $\mathrm{H}_{2} \mathrm{O}$ & $\begin{array}{l}45-60-75- \\
95 \% \text { ethanol } \\
\text { Pure EOH }\end{array}$ \\
\hline Mix & $\begin{array}{l}\text { cold } \\
\text { glutaraldehyde } \\
\text { and } \mathrm{OsO}_{4}(1: 2)\end{array}$ & & $\begin{array}{l}2 \mathrm{~g} / 100 \mathrm{ml} \\
\mathrm{H}_{2} \mathrm{O}\end{array}$ & $\begin{array}{l}\text { Dilute 45-60- } \\
75-95 \% \mathrm{ml}\end{array}$ \\
\hline Add & $\begin{array}{l}0.3-0.4 \mathrm{ml} \text { of the } \\
\text { mixture per } \\
\text { capsule }\end{array}$ & $\begin{array}{l}\text { 0.3-0.4 ml } \\
\text { per Capsule }\end{array}$ & $\begin{array}{l}0.3-0.4 \mathrm{ml} \text { per } \\
\text { Capsule }\end{array}$ & $\begin{array}{l}0.3-0.4 \mathrm{ml} \\
\text { per capsule }\end{array}$ \\
\hline Time & one hour & 2-3 min. & one hour & $\begin{array}{l}5 \text { min. per each } \\
\text { concentration } \\
10 \text { min. twice } \\
\text { in pure } \mathrm{EOH}\end{array}$ \\
\hline Comments & $\begin{array}{l}\text { on ice; use fume } \\
\text { cupboard and } \\
\text { heat } \\
\text { resistant capsules }\end{array}$ & $\begin{array}{l}3 \text { rinses; } \\
\text { centrifuge at } \\
1000 x g \text { each } \\
\text { time }\end{array}$ & $\begin{array}{l}\text { Room } \\
\text { temperature; } \\
\text { fume cupboard }\end{array}$ & $\begin{array}{l}\text { Centrifuge } \\
\text { at } 1000 x g\end{array}$ \\
\hline Reference & $\begin{array}{l}\text { Hirsch and } \\
\text { Fedorko, [2] }\end{array}$ & $\begin{array}{l}\text { Glauert } \\
{[12]}\end{array}$ & $\begin{array}{l}\text { Hirsch and } \\
\text { Fedorko [2] }\end{array}$ & $\begin{array}{l}\text { Glauert } \\
{[12]}\end{array}$ \\
\hline
\end{tabular}

II

\begin{tabular}{|l|l|l|l|l|}
\hline & Dehydration 2 & Dehydration 2 & Embedding & Polymerization \\
\hline Prepare & $\begin{array}{l}\text { Propylene oxide } \\
\text { \& EOH }\end{array}$ & $\begin{array}{l}\text { Resin \& } \\
\text { Propylene oxide }\end{array}$ & $\begin{array}{l}\text { Resin. DDSA. } \\
\text { BDMA }\end{array}$ & - \\
\hline Mix & $1: 1$ & $\begin{array}{l}\text { Few drops of } \\
\text { resin; } 1 ; 2: 1 \\
\text { propylene oxide }\end{array}$ & $\begin{array}{l}10 \mathrm{ml} \text { Araldite } \\
\text { Cy } 212+10 \mathrm{ml} \\
\text { DDSA+0.4 ml } \\
\text { BDMA* }\end{array}$ & - \\
\hline Add & $\begin{array}{l}\text { 0.3-0.4 ml per } \\
\text { capsule, then } \\
\text { pure prop. Oxide }\end{array}$ & $\begin{array}{l}0.3-0.4 \mathrm{ml} \text { per } \\
\text { capsule }\end{array}$ & $\begin{array}{l}\text { Fill the capsule } \\
\text { twice }\end{array}$ & $\begin{array}{l}\text { Fill the capsule } \\
\text { with resin; } \\
\text { label it. }\end{array}$ \\
\hline Time & $\begin{array}{l}5 \text { min. } \\
10 \text { min. each } \\
\text { Including }\end{array}$ & 10 min. each. & 1 hour at $100^{\circ} \mathrm{C}$ \\
\hline Comments & $\begin{array}{l}\text { Centrifuge } \\
\text { at } 1000 x g \text { if } \\
\text { required }\end{array}$ & $\begin{array}{l}\text { Centrifuge at } \\
1880 x g .\end{array}$ & $\begin{array}{l}\text { Centrifuge at } \\
1880 x g .\end{array}$ & $\begin{array}{l}\text { Leave capsule } \\
\text { lids open }\end{array}$ \\
\hline Reference & $\begin{array}{l}\text { Glauert, 1974. } \\
\text { Glauert, 1974. }\end{array}$ & Glauert, 1974. & Glauert, 1974. \\
\hline
\end{tabular}

*Similar results were obtained with Araldite CY212, 6 g.; DMP 0.65 g Epon 812, 7 $5 \mathrm{~g}$. and DDSA, $18 \mathrm{~g}$. as used in Electron Microscopy Unit, Wye College.

Table 1: Fast technique for fixing, dehydrating, embedding and polymerizing mitochondrial and cell suspension pellets for tem in about six hours.

sodium cacodylate buffer. After gentle agitation the $2.5 \%$ gluteraldehyde solution was placed on ice in the fume cupboard [2].

d) Glutaraldehyde osmium tetroxide fixative: This mixture was prepared by adding one part of glutaraldehyde $2.5 \%$ solution to two parts of $\mathrm{Os}_{4} 2 \%$ solution in a test tube. The operation was performed in the fume cupboard and the mixture kept on ice to avoid browning [3]. The amount of material to be prepared was proportional to the number of capsules being treated assuming 0.3 to $0.4 \mathrm{ml}$ to be required per capsule.

e) Uranyl acetate as post-fixative: The $2 \%$ solution was prepared fresh and kept in the fume cupboard, covering the container with aluminum foil [12].

f) Resin: Epoxy resin Araldite Cy 212 was mixed with the hardener DDSA in the proportion of $10 \mathrm{ml}$ of each with $0.4 \mathrm{ml}$ of the accelerator BDMA [12]. The ingredients were added in the order described, in a disposable plastic container and mixed mechanically for 20 minutes.

g) Capsule holding device: A piece of aluminum foil of $20 \times 12 \mathrm{~cm}$ was successively folded in half up to a width of about $2 \mathrm{~cm}$. Te strip was 
placed horizontally on a laboratory bench and a TAAB capsule placed horizontally on one end of the strip, with the capsule lid and stopper just to the outside of it. The strip was then tightly wrapped once around the capsule pressing the foil against its bottom. A second capsule was placed in the same way besides the first one, and the strip wrapped again once, tightly, against both capsules pressing the foil against their bottom. A third and fourth capsule were added in turn repeating the same procedure and the remaining strip was wrapped against the four capsules pressing the foil at their bottom. A piece of autocidiving tape was then wrapped tightly around the device which was placed into an oxoid aluminum cap.

In order to lift the device a piece of folded aluminum foil had previously been placed inside the cap allowing easy handling of the capsules. The holding device was secured laterally to the oxoid cap with autoclaving tape. The capsules could be removed easily each time it was necessary or convenient to do so. This device proved to be satisfactory for the work on ice in the fume cupboard, centrifugation, and polymerization.

For centrifugation holders were maintained slightly above the edge of the centrifuge tubes by putting 3 empty oxoid caps inside the $\phi 3 \mathrm{~cm}$ centrifuge tubes. Care was taken to avoid placing the sharp edges of the caps against one another to prevent capsules from becoming crushed at high speed.

h) TAAB Capsules: With the high temperature employed the ordinary capsules used to polymerize the resin lost their shape and start to melt at $95^{\circ} \mathrm{C}$. Aluminum foil moulds made by pressing strips of foil against a capsule retained their shape at $100^{\circ} \mathrm{C}$ but were very difficult to remove later from the polymerized block. However the TAAB heat-resistant capsules proved to be very satisfactory, supporting temperatures up to $120^{\circ} \mathrm{C}$ without showing any adverse effects.

i) Mitochondrial and cell pellets: In preparation for fixation, three replicate heat resistant $\mathrm{TAAB}$ capsules were filled with about $0.5 \mathrm{ml}$ of the mitochondrial suspension or cell suspension from each treatment. The labeled capsules with their lids closed were placed on the aluminum holder device previously described and centrifuged at $500 \mathrm{~g}$ for 2 minutes to collect the pellet. The supernatant was carefully extracted with a syringe leaving a very small amount of liquid over the pellet so as to prevent any disturbance. The pellet was washed by resuspending it in $0.4 \mathrm{ml}$ of fresh medium, centrifugating and removing the supernatant. The holders with the capsules were transferred into a fume cupboard on ice for processing for electron microscopy.

j) Fixation and post-fixation: The fixatives, used to stabilize the cells were glutaraldehyde and osmium tetroxide, followed by a postfixation treatment with uranyl acetate. The two fixatives were used together. Before the post-fixation the pellet was carefully washed because uranyl acetate reacts with the cacodylate buffer in which the fixatives are dissolved.

k) Glutaraldehyde $2.5 \%$ plus osmium tetroxide $2 \%$ fixative: The two fixatives were prepared separately in $0.1 \mathrm{M}$ cacodylate buffer at $\mathrm{pH}$ 7.4 as previously described. One part of the glutaraldhyde solution and two parts of osmium tetroxide solution were mixed in a test tube on ice. A 0.3-0.4 aliquot of the mixture was added to each capsule for one hour with the lids closed. The liquid was then removed with a syringe leaving a small amount over the pellet and disposed in alcohol to detoxify the osmium [12].

1) Uranyl acetate post-fixation: The pellets were washed three times with $0.3-0.4 \mathrm{ml}$ of glass distilled water being centrifuged at about
$1000 \mathrm{~g} \mathrm{x}$ in a bench MSE centrifuge for 2 minutes each time. The $2 \%$ uranyl acetate was added to each capsule (0.3-0.4 ml). With their lids closed they were kept at room temperature in a fume cupboard for one hour. The liquid was then removed with a syringe, leaving a small amount over the surface of the pellet.

m) Dehydration: The mitochondrial pellet was dehydrated by passing through an alcohol series (redistilled ethanol) of the following af, enlopem acosisurnt5-60-75-95\% for 5 minutes each and two final immersions in $100 \%$ alcohol for 10 minutes each, removing the alcohol each time with a syringe. Centrifugation was made only when required to maintain the pellet.

n) Embedding: Being viscous, the resin does not penetrate the material very readily. Since, it is essential that the resin enters all parts of the mitochondria completely before polymerization so as to allow satisfactory sectioning of the specimen it has to be introduced gradually. Starting with a mixture of a few drops of resin in propylene oxide the resin concentration was increased gradually after every change of 10 minutes up to two parts of resin for one part of propylene oxide. Centrifugation was required at about $1000 \times \mathrm{g}$ in the bench MSE centrifuge for 5 minutes each. The total time of this procedure was about 45 minutes, and seemed to be critical in order to facilitate the final pure resin embedding.

o) Resin: Finally after two changes of pure resin for 10 minutes each and centrifugation at $1880 \mathrm{x}$ g in the bench centrifuge for 10 minutes each time, the capsules were filled with resin up to the stopper of the lid, labelled and centrifuged at full speed for 2-3 minutes to get rid of any air bubbles. It was found that tilting the capsule was an easy way of draining the resin and, when it started to flow out, the capsule was turned rapidly upside down allowing the pellet to adhere to the bottom of the capsule. When the pellet was difficult to form in the resin the polypropylene-resin mixture treatment was repeated as described. Another procedure consisted of transferring the pellet to another capsule and filling slowly with resin.

p) Resin polymerization: The oxoid caps holding the labeled heat resistant capsules with their lids left open were then placed in an oven, previously set at $100^{\circ} \mathrm{C}$, for one hour, and subsequently allowed to cool on the laboratory bench. The blocks were then removed by cutting the capsules open with a razor blade which required extra care so as not to damage the tips of the blocks which contained the specimens, heat resistant capsules being rather hard to cut than ordinary ones.

q) Trimming the block: To estimate the sectioning properties of the resin to be used two or three blocks without pellets were prepared as described above, mounted in a G block holder and trimmed to a trapezoidal pyramid shape according to LKB Ultra tome III instruction manual.

r) Sectioning: New glass knives with good straight edges were selected and troughs fixed to them for collecting the sections on water. The parallel sides of the block were set parallel to the knife edge which was brought up to the specimen very closely. The knife was then moved to the left to allow the first contact of the block to be with an inferior portion of the knife, usually at its right side. The macro feed reduction gear knob was advanced by stepwise movements of about $1 \mathrm{~mm}$ and full swings of the specimen arm until the first contact was made. Then the knife stage was moved slightly to the right to ensure that its sharpest portion would cut the sections. The automatic feeder was set at about $700 \mathrm{~A}^{\circ}$ in the LKB Ultra tome III. When the knife was away from the specimen it was advanced by using the micro feed knob until a complete section was obtained. If the knife was too near the specimen 
and the first cut was too thick, the knife was moved to the right through a distance equivalent to the width of the trapezoid. The knife was then carefully placed in contact with the specimen by the micro feed knob. The ribbon began to appear at the edge of the knife and started floating on the water surface of the trough. It was found preferable at this stage for the operator to keep some distance from the microtome as any involuntary movement while touching the equipment or even breathing could move the water causing the pale gold ribbon to break. A ribbon of about 12 sections proved to be a satisfactory number on the grid after the sections have been stretched with chloroform fumes, and changed in color from pale gold to silver. It was observed that silver sections once stretched with chloroform became so thin that later staining gave insufficient contrast with the small amount of tissue present. Sections were picked up with 100 mesh grids coated with forever. The grid held with tweezers was previously immersed in $1 \%$ teepol and then in water to reduce the surface tension after introducing the grid vertically into the water. Once the grid was adjusted so that ribbon came to lie across the middle, it was lifted carefully but fairly rapidly. When the ribbon came to lie at the edges of the grid it was practically impossible to make observations or to take micrographs in the electron microscope. The procedure was similar to that described in the LKB Ultra tome III instruction manual.

s) Staining: Staining was carried out to increase contrast and get optimum definition of the structure of the organelles. Grids holding the specimen were dried by placing velin tissue in the middle of the forceps just touching the edge of the grid, which was then kept on a sheet of dry filter paper in a petri dish. Drops of a saturated alcoholic solution of uranyl acetate were placed either on dental wax or on a polypropylene sheet in a petri dish and the grid was then immersed in the drop for 10 minutes. After washing the grid with running glass distilled water it was dried again using filter paper to remove the water between the prongs of the forceps close to their tip. Lead citrate staining was also used in the same manner as for uranyl acetate. After a final drying with velin tissue the grids were ready to be observed in the TEM.

\section{Results}

\section{Experiments defining essential techniques}

The goal of these experiments was to find appropriate procedures to obtain abundant callus to get isolated cells and isolated mitochondria of soybean of consistent behavior of respiratory, metabolic and electron microscope studies.

The steps involved in this investigation were seed sterilization, tissue culture of cotyledons and preparation of suspensions of isolated cells and isolated mitochondria.

\section{Seed sterilization}

Ethanol followed by a commercial formulation of sodium hypochloride (BDH): The procedure was inadequate to control bacterial contamination. Then the mercuric chloride method was tried.

Mercuric chloride: The sterilization procedure with $\mathrm{HgCl}_{2}$ proved to be very effective in controlling both fungal and bacterial contamination, though the seedlings often showed abnormalities such as the thickening of the main root or proliferation of secondary roots.

Sometimes the main root grew upwards showing a probable disturbance in its geotropic mechanism. These abnormalities may be attributed to the fact that 3 rinses in sterile water for 1 minute each probably were not enough to remove all $\mathrm{HgCl}_{2}$ from the seed coats. With 5 or more rinses in sterile water abnormalities were largely eliminated.

\section{Callus initiation}

The callus production was very satisfactory but developing only on cut surfaces, about 5 days after placing the cotyledon pieces on agar and Murashige and Skoog's medium, with $0.5 \mathrm{mg} / \mathrm{l} 2,4-\mathrm{D}$ and $0.1 \mathrm{mg} / \mathrm{l}$ of kinetin in the light at $23^{\circ} \mathrm{C}$. The agar medium already mentioned and the scrapping of both cotyledon surfaces were used as a routine practice for callus initiation in the light at $23^{\circ} \mathrm{C}$. In experiments in which the cotyledons were cut longitudinally callus again grew only on the cut surfaces and the explant tended to curl upwards. The fact that callus growth was restricted to cut surfaces was attributed to the presence of the cotyledonary epidermis. A few experiments were conducted to study the effect of the removal of the cotyledonary epidermis on callus growth. Callus grew uniformly on scrapped surfaces and as a routine practice both surfaces of the cotyledons were scrapped before sectioning. Callus growth was commonly observed about 5 days after placing the scrapped cotyledon pieces on agar medium.

The Figure 1 shows uniform growth of callus from the scrapped upper surface while no callus grew on the lower surface with the epidermis left intact. This was attributed to some inhibitory effect related to the presence of the cotyledonal epidermis. There was no noticeable difference between callus samples taken at different times during the subculture interval of 0-14 days.

The amount of callus produced in $1-\mathrm{B} 5$ medium at $23^{\circ} \mathrm{C}$ in a growth chamber both in continuous light and dark was rather small. Murashige and Skoog's medium with $0.5 \mathrm{mg} / \mathrm{l}$ of $2,4-\mathrm{D}$ and $0.1 \mathrm{mg} / \mathrm{l} \mathrm{kinetin}$ produced greater amount of callus in the light. After several trials it was confirmed that Murashige and Skoog medium gave reliable growth and it was used routinely thereafter.

\section{Cell and mitochondria suspensions}

Once the suitable techniques for the consistent production of abundant callus was obtained, it was necessary to develop an adequate procedure for the production of isolated mitochondria for citochrome $\mathrm{c}$ oxidase studies and isolated cells for respiratory, metabolic and electron microscopy studies.

Cell viability: The percentage of viability of the cell suspensions assessed with fluorescein diacetate according to Widholm [13] was 87\%, which was very satisfactory for the different experiments. Usually $1 \mathrm{~g}$ of callus in $2 \mathrm{ml}$ of assay medium gently shaken was a routine procedure to get excellent and consistent population of isolated cells with few clumps Figure 2.

Electron microscopy: The fast method described here allowed treatment with herbicides, fixation, dehydration, embedding and

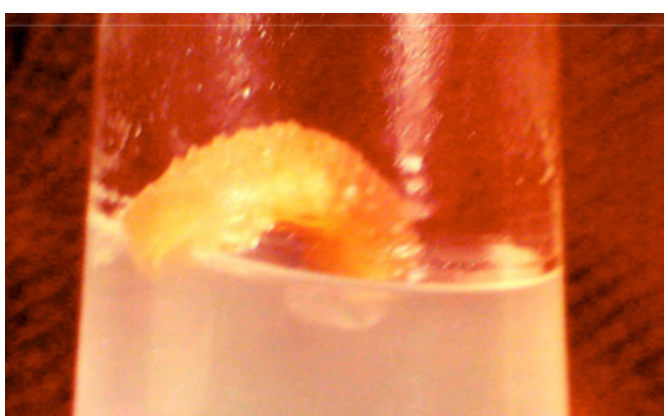

Figure 1: Soybean cotyledon piece on sterile nutrient agar. Note uniform callus growth on upper surface from which epidermis was removed, and absence of callus on the lower surface with intact epidermis. 
Citation: Colmenares HC (2013) Fast Transmission Electron Microscope (TEM) Technique for Observing Isolated Mitochondria of Soybean (Glycine max (L.) Merr.) in about Six Hours. Adv Pharmacoepidem Drug Safety 2: 136. doi:10.4172/2167-1052.1000136

Page 5 of 6

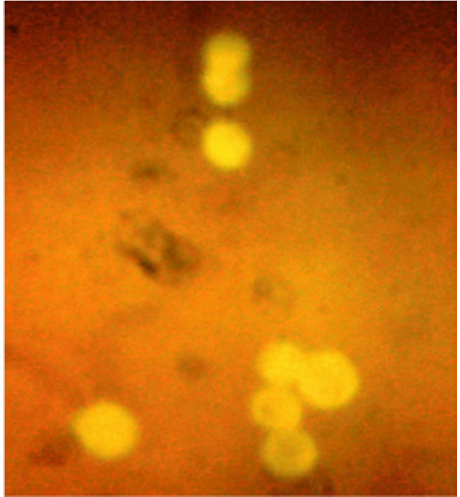

Figure 2: Live isolated cells of soybean stained with fluorescein diacetate viewed under ultraviolet light.

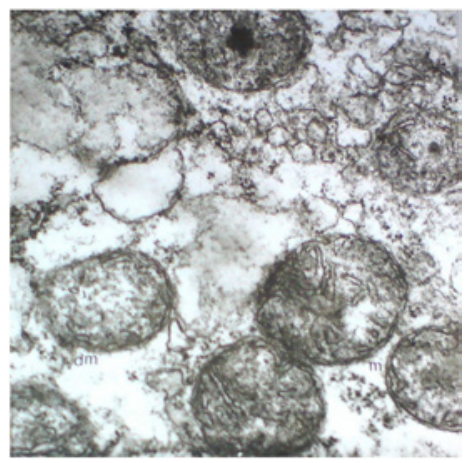

Figure 3: Isolated mitochondria $(\mathrm{m})$ with outer and inner structure well defined; deteriorating mitochondrion $(\mathrm{dm})$ with outer membrane clearly damaged. $\times 50,000$

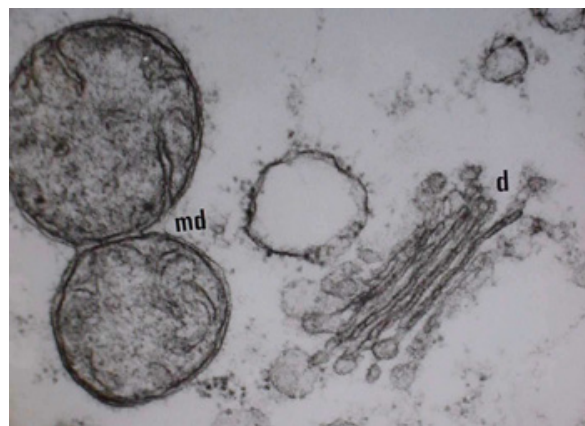

Figure 4: Dictyosome (d), showing cysternae clearly distinguishable; dividing mitochondrion (md) showing the original outer membrane. x 60.000.

polymerization in about six hours. The materials were essentially the same as those used in the conventional technique for the preparation of plant material for electron microscopy studies.

The fast technique for TEM is based on procedures already proved for human leukocytes [2] and in animal tissue [3]. This fast technique is a combination of methods which were shown to be satisfactory by several authors $[2,3,11,12]$. In early trials it was found that while the technique gave generally satisfactory preservation of fine structure, the plasmalemma had a tendency to separate from the cell wall when polymerization was made at $100^{\circ} \mathrm{C}$. However post-fixation with aqueous uranyl acetate solution eliminated the difficulty. Also

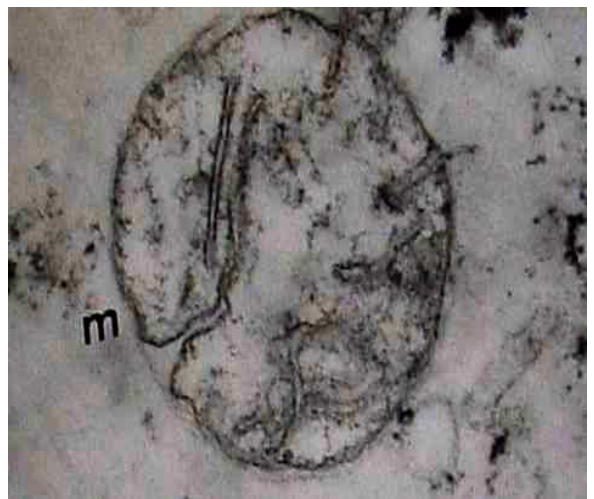

Figure 5: Isolated mitochondria $(\mathrm{m})$, with outer and inner membranes well preserved as observed in intact cells. $\times 30,000$.

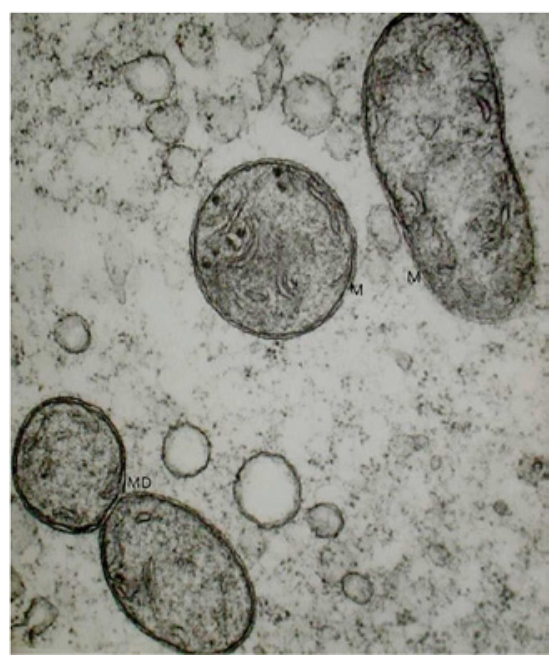

Figure 6: Mitochondria $(\mathrm{m})$ usually round or elongated, with both outer and inner membranes well defined; dividing mitochondrion (md). x 60.000.

it was found necessary to rinse the pellet in water after fixation with glutaraldehyde- osmium to avoid a precipitation from forming. This observation corroborates Glauert's [12] observation that uranyl acetate reacts with cacodylate buffer.

The heat-resistant TAAB capsules gave good results for polymerization at $100^{\circ} \mathrm{C}$. Ordinary capsules melt at $95^{\circ} \mathrm{C}$. It was generally found convenient to assess the suitability for sectioning of blocks prepared from a particular batch of resin alone, usually in a duplicate set of capsules. Subsequently the specimen blocks consistently showed the same quality. Resin was prepared freshly when needed as it tended to become more viscous in storage. In spite of the use of uranyl acetate as a post-fixative it was observed that the contrast in the electron microscope was greatly increased when uranyl acetate followed after washing by lead citrate during the staining procedure.

\section{Determination of the Integrity of Isolated Mitochondria}

\section{a. Mitochondrial extraction}

The methods used in this research for soybean mitochondria extracts were similar to the procedures used for mitochondria extraction from animal sources. There is difference in the mitochondria preparation of different plant species. Laties [14] found that cauliflower 
Citation: Colmenares HC (2013) Fast Transmission Electron Microscope (TEM) Technique for Observing Isolated Mitochondria of Soybean (Glycine $\max ($ L.) Merr.) in about Six Hours. Adv Pharmacoepidem Drug Safety 2: 136. doi:10.4172/2167-1052.1000136

Page 6 of 6

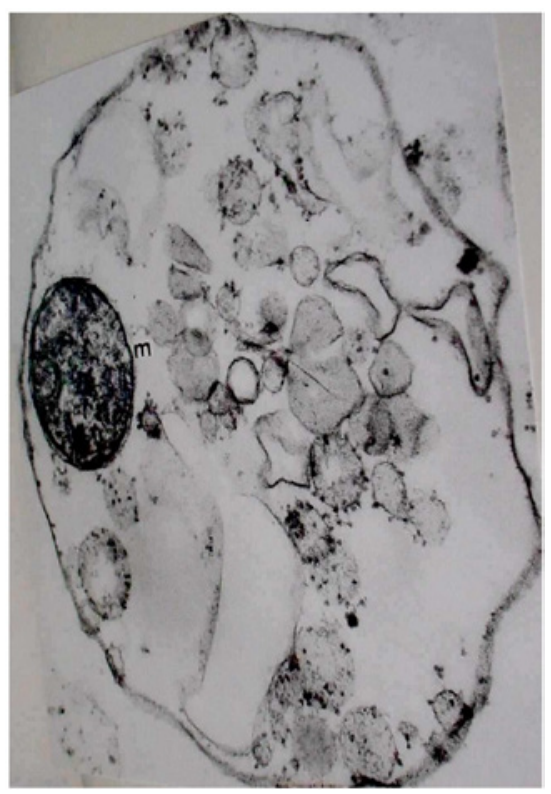

Figure 7: Mitochondrion $(\mathrm{m})$, surrounded by a membranous structure resembling an autophagic vacuole. (Nishizawua and Mori, (1978). x 50,000.

mitochondria are extremely sensitive to the tonicity of the extracting medium.

As a routine practice mitochondria were extracted using the medium described by Axelrod [10]. The plant material was disrupted to subcellular level and the desired particles were separated by differential centrifugation (Figures 3-7).

\section{References}

1. Cardenas H (1979) Some effects of low doses of simazine and bentazone on fine structure and metabolism of soybean cells. Imperial College London 217.

2. Hirsch JG, Fedorko ME (1968) Ultrastructure of human leukocytes after simultaneous fixation with glutaraldehyde and osmium tetroxide and "postfixation" in uranyl acetate. J Cell Biol 38: 615-627.

3. Trump BF, Bulger RE (1966) New ultrastructural characteristics of cells fixed in a glutaraldehyde-osmium tetroxide mixture. Lab Invest 15: 368-379.

4. Cowdry NH (1917) A comparison of mitochondria in plant and animal cells. Biol Bull 33: 196-228.

5. Rugarli El, Langer T (2012) Mitochondrial quality control: a matter of life and death for neurons. EMBO J 31: 1336-1349.

6. Gambor OL (1975) Callus and cell culture. 1-10. "in" Plant Tissue Culture Methods, eds. O. L. Gambor and L. R. Weter. National Research Council of Canada, 110.

7. Walker JC (1957) Plant Pathology.2nd ed. McGraw Hill Book Company, Inc. New York 707.

8. Yeoman MM (1973) Tissue (callus)-cultures-techniques. 31-58. "in Plant Tissue and Cell Culture. H.E.Streeet, ed.Blackwell Scientific Publications. Oxford 503.

9. Skipp RA, Selby C, Bailey JA (1977) Toxic effects of phaseolin on plant cells. Physiological Plant Pathology. 10: 221-227.

10. Axelrod B (1955) Preparation of mitochondria from plants. Methods in Enzymology 1: 19-22.
11. Hayat MA (1970) Principles and techniques of electron microscopy. Biological applications.Van Nostrand Reinhold Company 1: 149-150.

12. Glauert AM (1974) Fixation, dehydration and embedding of biological specimens. 1-207. "in" Practical Methods in Electron Microscopy. Vol. 3. ed. A M. Glauert. North Holland Publishing Company. Amsterdam 353.

13. Widholm JM (1972) The use of fluorescein diacetate and phenosafranine for determining viability of cultured plant cells. Stain Technol 47: 189-194.

14. Laties GG (1954) The Osmotic Inactivation in situ of Plant Mitochondria Enzymes. J Exp Bot 5: 49-70. 